\title{
Nd isotope fingerprinting reveals anthropogenic impact on the sediment routing processes in the Huanghe catchment
}

\author{
Yulong GuO, ShOUYE YANG, CHAO LI
}

State Key Laboratory of Marine Geology, Tongji University, Shanghai, 200092, China

The heterogeneity of $\mathrm{Nd}$ isotopic composition in the Huanghe sediments mainly reflects the geomorphological and sedimentary processes in the Huanghe river under the influence of human activities. Due to the cascade hydroelectric engineering projects in the Huanghe upstream, the contribution of the Songpan-Ganzi block in the source area is rapidly reduced downstream. The Loess Plateau in the middle Huanghe reaches suffers intense erosion, and contributes a great amount of materials to the Huanghe in this section. We proposed a novel correction method to constrain the $\mathrm{Nd}$ isotope composition of average UCC in the North China Craton (NCC), making it possible to mathematically unmix the sediments in the lower Huanghe. Two downstream stations show a signal of low $\varepsilon N d$ from proximal materials from the NCC, confirming the view that the channel-bed in the lower reaches now experiences erosion rather than deposition in recent years. Both water and sediment discharges of Huanghe River has decreased dramatically in recent decades based on hydrological stations records, and the deposition-erosion patterns of the downstream channels has changed significantly. Anthropogenic activities including reservoirs/dam construction, soil and water conservation, and Huanghe Diversion Project are the main reasons that induce the radical change of Huanghe's source to sink processes in the past few decades. The great impact of human activities on the Huanghe sediment routing processes can be traced back to $\sim 3000$ a BP. In recent years, the sediment flux of the Huanghe has been reduced to the level before human intervention, meanwhile the Huanghe sediment routing system has also undergone profound changes. In the context of global rivers under impact of strong human activities, the stability of river sediment routine system and the representativeness of modern sediment samples should be taken seriously.

Key words: Sediment routine system of Huanghe, $\mathrm{Nd}$ isotopes, Human impact 